\title{
A PEDAGOGIA SOCIALISTA DE MAKARENKO: NOTAS PEDAGÓGICAS
}

\author{
Lucíola Andrade Maia ${ }^{1}$
}

\begin{abstract}
RESUMO
Este texto, para além de divulgar a obra e as ideias do educador socialista ucraniano Anton Makarenko e sua eminente luta a favor da educação, busca refletir sobre a relevância de seu legado pedagógico para a formação humana. Makarenko dedicou sua vida a educar, elaborar e construir um processo educativo fundado no pensamento socialista. Seu trabalho foi especialmente dirigido à educação de crianças e adolescentes abandonados e oprimidos pela estrutura da ditadura czarista no Império russo. A pedagogia de Makarenko se notabilizou pela beleza de seu trabalho e de sua obra educativa e social, articulada nas instâncias ditas como socialismo ou socialismo real. Mormente seu trabalho em conjunto com outros educadores socialistas, fez da educação uma arte de ensinar e aprender, criando uma escola e uma vida em movimento. Movimentos e mobilizações políticas constantes constituindo, no cotidiano das relações e das lutas sociais, verdadeiras oficinas de arte-educação, vida e trabalho. O pedagogo associou a educação às necessidades dos coletivos, a realidade histórica que a comunidade e a sociedade necessitavam à época. Autor de vários livros como Poema Pedagógico, Bandeiras nas Torres, Livro dos pais e Problemas da educação escolar, o aludido educador descreve, em suas obras, sua experiência educativa na União Soviética versando sobre a edificação da escola socialista. Esses volumes marcam a vida de Makarenko e a educação crítica, abordam as primeiras lições do socialismo na União Soviética trabalhando também, entre outros relevantes tópicos, a fundação da banda de música, do grupo de teatro e suas múltiplas atividades artísticas e culturais desenvolvidas pela coletividade na Colônia Górki. O trabalho desse educador na Colônia Gorki e Comuna Dzerjinski mostra a possibilidade real dos homens-educadores darem passos transformadores nas suas vidas. A história de vida de Makarenko, as lutas sociais, as falas, os discursos pedagógicos, a práxis social, o seu engajamento político na elaboração de uma teoria da educação e de uma escola socialista fizeram desse homem-educador um autêntico defensor dos interesses dos desvalidos.
\end{abstract}

Palavras-chaves: Pedagogia. Socialista. Formação Humana. Anton Makarenk.

\begin{abstract}
This text, in addition to promoting the work and ideas of the Ukrainian socialist educator Anton Makarenko and his eminent struggle for education, seeks to reflect on the relevance of his pedagogical legacy for human development. Makarenko devoted his life to educate, develop and build an educational process based on the socialist thought. His work was particularly focused on the education of children and adolescents abandoned and oppressed by the structure of the Tsarist dictatorship in the Russian Empire. Makarenko's pedagogy became famous for the beauty of his educational and social work, articulated in said instances as socialism or real socialism. Especially his work together with other socialist educators turned education into the art of teaching and learning, creating a school and a life in motion. Movements and constant political mobilization constituting, in daily social relations and

\footnotetext{
${ }^{1}$ Professora Dra. da Universidade Estadual do Ceará (UECE), do curso de Pedagogia do Centro de Educação. Coordena na UECE a pesquisa de Iniciação Cientifica: Educação, Marxismo e Formação Humana em Makarenko e Florestan Fernandes nos séculos XX e XXI. E-mail: luciolamaia1313@gmail.com
} 
struggles, real workshops of art-education, life and work. The educationalist associated the education to the needs of the collective, the historical reality that both community and society needed at the time. Author of several books, such as The Pedagogical Poem, Flags on Towers, The Book for Parents and Problems of Soviet School Education, the aforementioned educator describes, in his works, his educational experience in Soviet Union dealing with the building of the socialist school. These volumes mark the life of Makarenko and the critical education, and they address the first lessons of socialism in the Soviet Union also working, among other relevant topics, the foundation of the music band, the theater group and its many artistic and cultural activities developed by the Gorky Colony community. This educator's work at Gorky Colony and Dzerzhinsky Commune shows the real possibility of meneducators to take transforming steps in their lives. The life story of Makarenko, the social struggles, the speeches, the pedagogical discourses, social praxis, his political engagement in the development of a theory of education and a socialist school turned this man-educator into a true defender of the interests of the underprivileged.

Palavras-chaves: Pedagogy. socialist. Human development. Anton Makarenko.

\section{INTRODUÇÃO}

Talvez os críticos não sejam conscientes o suficiente sobre como a estrutura social é dolorosa para os mais pobres. O sofrimento é geralmente parte de um sistema imposto. A conscientização leva as pessoas a se perguntarem como resolver problemas como a fome. É com repressão? (Istvan Mészáros).

Nossa explanação tematiza a importância do pensamento de Anton Semiónovitch Makarenko para a formação do educador crítico e suas contribuições para a educação contemporânea. Makarenko é um autor socialista nascido em solo ucraniano. Durante as primeiras décadas da Revolução Russa (1917), desenvolveu um trabalho com crianças e adolescentes em sua maioria, órfãos de pai e mãe na Ucrânia, uma das Repúblicas Socialistas Soviéticas $^{2}$ devastada na sua estrutura física pela Primeira Guerra Mundial (1914-1918) e pelo processo revolucionário em 1917. A experiência do educador na Colônia Gorki ${ }^{3}$ e Comuna Dzerjinski, mostra a possibilidade real dos homens-educadores darem passos transformadores

\footnotetext{
${ }^{2}$ Países e regiões que faziam parte de URSS e passaram e adotar a sinonímia República Socialista Soviética: Rússia, Ucrânia, Bielo-Rússia, Uzbequistão, Cazaquistão, Geórgia, Azerbadijão, Lituânia, Moldávia, Letônia, Kirguízia, Tadjiquistão, Armênia, Turcomênia, Estônia.

3 Na Colônia Górki, Makarenko desenvolveu um trabalho educativo ganhando notoriedade no mundo. O educador construiu um processo educativo revolucionário capaz de educar e conscientizar crianças e adolescentes que viviam abandonados nas ruas e na miséria. As crianças não tinham roupas, nem comida. Nem pais, nem parentes. Esse autor ucraniano transformou os educandos realizando um trabalho coletivo de grande envergadura em músicos, engenheiros, médicos, pilotos, artistas, cientistas.
}

\begin{tabular}{|c|c|c|c|c|}
\hline Revista Dialectus & Ano 2 & n.7 & Setembro-Dezembro 2015 & p. 68-81 \\
\hline
\end{tabular}


nas suas vidas. A história de vida de Makarenko ${ }^{4}$, as lutas sociais, as falas, os discursos pedagógicos, a práxis social, o seu engajamento político na elaboração de uma teoria, de uma educação, de uma escola socialista fez desse homem-educador um autêntico defensor da causa dos desvalidos.

Nossa exposição versa também sobre a relevância da obra social e teórica de Makarenko para a formação do educador e do novo homem, enfatizando a colaboração do autor e sua luta pela educação discutindo os problemas educacionais e a falta de acesso do povo russo a educação, e as dificuldades para fazer um curso de nível superior. Período bastante difícil à época, pois, na vigência do Império Russo, em todo o seu território a imensa maioria da população não tinha acesso à escola. O Império Czarista russo contava com mais de 152 nacionalidades, apenas 30 tinham alfabeto próprio, variados dialetos e línguas não codificadas. Nesse contexto, repleto de contradições, Anton Semiónovitch Makarenko ${ }^{5}$ filho de pais ferroviários, professor de língua russa, conseguiu concluir o curso de Pedagogia em $1905^{6}$, trazendo importantes publicações para a pedagogia e as ciências humanas tanto em seu país de origem como em outras partes do mundo.

Apreciar e divulgar a vida e a obra de um autor como Makarenko, é disseminar sua própria história e compreender, através da dinâmica da sua vida, das lutas sociais, o que o transformou num dos maiores educadores do planeta. Para mostrar as adversidades históricas pelas quais passou o pedagogo em relevo e o proletariado russo, tomemos como exemplo o Domingo Sangrento de São Petersburgo que exterminou mais de 500 pessoas em $1905^{7}$. Diversos protestos foram organizados, passeatas, paralisações nos portos, nas fábricas, lutas que se estenderam até o período da Revolução de outubro de 1917. Realçamos esses momentos históricos e políticos em que esse educador de nome Makarenko forma sua consciência crítica e suas convicções políticas. Nesses momentos vivos se forma e é formado, contribuindo o pedagogo ucraniano para a transformação de outros homens como praticou e teorizou durante sua vida dedicando 32 anos a educação, a infância e adolescência dos russos

\footnotetext{
${ }^{4}$ Mais informações ver em: MAIA, Lucíola Andrade \& PINHEIRO, Carísia Maia. Mestres da educação socialista: Anton Makarenko e Florestan Fernandes. Fortaleza: Centro Cultural do Benfica, 2010.

${ }^{5}$ Sobre o tema, recomenda-se a leitura de relevante contribuição de LUEDEMANN, Cecília da Siveira. Anton Makarenko, vida e obra: a pedagogia da revolução. São Paulo: Expressão Popular, 2002.

${ }^{6}$ Informações mais detalhadas sobre a revolução de 1905 e sobre o Outubro Vermelho ver em: Trotsky. A Revolução de 1905. São Paulo: Global Editora, [s.d].

${ }^{7}$ Mais detalhes sobre a Revolução Russa, conferir nas seguintes obras de LÊNIN, V.I. O Estado e a revolução. São Paulo: Global Editora, 1987. Lênin. 1905- Jornadas socialistas. Contagem - Minas Gerais: Editora História, 1980. Lênin.V.I. Que fazer? São Paulo: Hucitec, 1988.
}

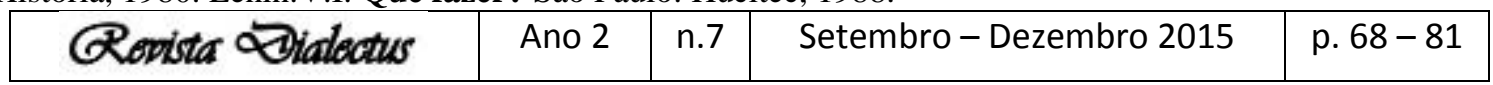


/ soviéticos. Desse modo, narra a escritora russa Belinky ${ }^{8}$ sobre a vida pedagógica makarenkiana, compreendemos que a citação é longa, mas relevante:

Se educar é uma tarefa difícil, mas difícil é reeducar. E foi essa a tarefa que Makarenko escolheu e assumiu ao criar suas colônias - seus coletivos - com a meta de salvar e recuperar essas crianças, transformando-as em cidadãos no mais pleno sentido da palavra. Makarenko reabilitou esses "menores" (como aqui são chamadas as crianças pobres), vítimas do período de guerra, os bezprizornies, infelizes pivetes e pixotes, lançados, órfãos, abandonados e desvalidos, na miséria, na vagabundagem, no vício, na prostituição, e mesmo na delinquência, tornaram-se homens e mulheres de verdade. A essa tarefa hercúlea, Makarenko devotou-se com admirável coragem, determinação e dedicação sustentado pelo seu comovido, mas jamais piegas, amor pelas crianças desprivilegiadas de seu país. Foi um desafio aparentemente invencível, que ele, no entanto, soube enfrentar com talento, audácia, e criatividade, conseguindo realizar seu ideal "a construção do ser humano novo", dentro de um novo contexto histórico através de uma luta penosa, na qual teve que se haver com poderosos "dragões": desde a labiríntica burocracia soviética e uma imensa falta de recursos materiais, até a resistência, chegando às vezes até a violência física, da parte dos educandos - semi-selvagens e mesmo delinquentes -, passando pelas críticas e oposições de pedagogos e pseudopedagogos oficiais, e pelos obstáculos criados por autoridades impositivas. (BELINKY apud CAPRILES, 1989, p.8). ${ }^{9}$

Makarenko fez da educação sua vida, da tarefa de educar um caminho para a transformação do homem em pensador revolucionário comprometido com a educação socialista. Designado pelo Comissariado do Povo (para delinquência juvenil) o então escritor Máximo Górki, nomeou Makarenko diretor da Colônia Górki. O renomado pedagogo abraçou a tarefa histórica de realizar um trabalho político e pedagógico segundo as teses do socialismo se transformando no precursor de uma práxis pedagógica socialista e numa referência em seu país e posteriormente no mundo. É o que demonstra essa passagem do autor:

A nossa causa da educação comunista, é um empreendimento novo a nível mundial. Se levarmos em consideração esferas do conhecimento como a técnica, a literatura e outras, veremos que sempre se recebe algo das gerações anteriores. No domínio da educação comunista, o assunto é ainda mais complicado, pois há apenas vinte anos estas palavras - a educação comunista - quase não se ligavam. E não nos envergonhamos absolutamente de dizer que, em muitos pormenores do nosso trabalho, somos ainda imaturos continuamos a ser e não pode ser de outro modo.

\footnotetext{
${ }^{8}$ Tatiana Belinky foi uma escritora russa, crítica literária, crítica de teatro e tradutora. Nasceu em Petrogrado em 1918, foi uma das mais importantes escritoras infanto-juvenis contemporâneas. Autora de mais de 250 livros. Chegou ao Brasil com dez anos de idade. Recebeu a cidadania brasileira e foi radicada em São Paulo durante mais de oitenta anos.

9 Trecho extraído do prefácio da obra de: CAPRILES, René. MAKARENKO: o nascimento da pedagogia socialista. [s.l.]: Scipione, 1989.
}

\begin{tabular}{|c|c|c|c|c|}
\hline QRomita Oialectus & Ano 2 & n.7 & Setembro - Dezembro 2015 & p. $68-81$ \\
\hline
\end{tabular}


Seria na verdade presunção afirmar que em apenas vinte anos tivéssemos condições de criar, finalizar e formar uma grande escola pedagógica completamente nova a escola da educação comunista. Nesse campo somos autênticos pioneiros e é próprio dos pioneiros enganarem-se. O mais importante é não temer os erros e atuar com audácia. (MAKARENKO, 2010, p. 114).

Nossa abordagem, para além de refletir sobre a temática em pauta, intenta divulgar a obra social e teórica de Makarenko ${ }^{10}$, por compreendermos que sua experiência, seus escritos pedagógicos trazem relevantes contribuições para a educação. As ideias do teórico foram difundidas em várias partes do mundo deixando um legado para a humanidade, principalmente para aqueles que trabalham com educação e ciências humanas. Para ilustrar nossa proposição, destacamos algumas obras do autor que orientam nossa inspiração teórica e nossas reflexões sobre a práxis ${ }^{11}$ docente, a saber: A marcha dos 30, A experiência metodológica na colônia infantil de trabalho, FD-1 - novela, Poema Pedagógico - 3 volumes, Tom Maior - teatro, Metodologia para a organização do processo educativo, Conferências sobre educação infantil, Livro dos pais 4 volumes, A felicidade, A Honra, Os anéis de Newton, Problemas da educação escolar Soviética, Bandeiras nas Torres, Aprendendo a viver, Um caráter verdadeiro, Em comissão de serviço, Da minha experiência de trabalho, As minhas concepções pedagógicas, cartas e artigos, Problemas da educação escolar.

Essas obras de Makarenko versam sobre variados temas, convergindo para princípios educativos dirigidos aos coletivos de educadores, à educação das crianças e adolescentes, aos pais de alunos, aos artistas, aos trabalhadores, a comunidade. Corroborando desse modo, com suas publicações que, posteriormente, ao longo da história se transformaram em verdadeiras referências pedagógicas para fundamentação das aulas de educadores da União Soviética.

\section{MAKARENKO, A REVOLUÇÃo RUSSA E A EDUCAÇÃO}

Com a queda do Império Tzarista Russo e o advento da Revolução Socialista Russa em outubro de 1917, um mar de transformações ocorre simultaneamente em todas as partes das Repúblicas Soviéticas. O anúncio do governo revolucionário de várias tarefas emergenciais da revolução impulsionou a reforma agrária, a preservação da cultura popular, o

\footnotetext{
${ }^{10}$ Makarenko além de ter sido influenciado por Máximo Górki, foi também na práxis e nas obras de Leon Tolstói, escritor no qual o pedagogo buscou inspiração pedagógica. Também influenciado pelos eminentes escritores e ativistas, Rousseau, Vladimir Lênin, Nadja Krupsakaia, considerada a fundadora da pedagogia socialista pré-escolar soviética.

${ }^{11}$ Sobre a práxis, conferir importante referência teórica em VÁZQUEZ, Adolfo Sánchez. Filosofia da práxis. São Paulo: Expressão Popular, 2007.
}

\begin{tabular}{|c|c|c|c|c|}
\hline QRomita Oialectus & Ano 2 & n.7 & Setembro - Dezembro 2015 & p. $68-81$ \\
\hline
\end{tabular}


acesso dos trabalhadores a escola e a universidade, a criação de centenas de grupos de folclore, dança, balé, música, cinema, investimento em esportes estímulo as artes, literatura e variadas formas de manifestações artísticas. No período referido veio o incentivo a educação como tarefa prioritária do governo socialista, assim foi a luta, a vida e a história de Makarenko, envolvido com a educação de seu país. Nessa linha de pensamento, Makarenko nos ensina:

Cada circulo deve ter seu dirigente responsável conhecedor deste tipo de trabalho. Se são os pedagogos desta instituição a dirigirem estes círculos é recomendável que cada pedagogo se encarregue apenas de um círculos e receba por este trabalho suplementar uma determinada compensação financeira. (MAKARENKO, 1986, p.174).

Ainda segundo o pedagogo ucraniano, autor de Problemas da educação escolar, na obra supracitada, escreve que podem se recomendados vários círculos de cultura objetivando ampliar os conhecimentos críticos dos educadores e educandos e a participação popular. São eles: de coro, dramático, literatura russa, literatura nacional, de instrumentos de sopros, de instrumentos de cordas, de instrumentos de percussão, de pintura, de trabalhos manuais, de dança, de fotografia, de investigações em ciências naturais, de amadores de rádio, de física e química, de línguas estrangeiras, desportivo, de contos, de xadrez e damas. (MAKARENKO,1986, p. 174).

Buscando Makarenko elaborar uma teoria socialista da educação forjada na luta, no cotidiano das vivências pedagógicas e das relações humanas, estudou e aprofundou teóricos que enfocam uma perspectiva de formação do novo homem com feições e práxis socialista. Uma educação rica em literatura socialista, casando teoria e prática pautada também nas artes cênicas, na literatura russa, no estudo dos clássicos da dramaturgia, dos escritores socialistas e libertários, por exemplo, Marx, Engels, Lênin, Tolstói ${ }^{12}$. Em relação a organização do teatro na Colônia Górki por exemplo, o pedagogo em tela relata:

Havia ensaios todos os dias em cada peça por inteiro. Em geral não dormíamos o suficiente. Há que ter em conta o facto de que muitos dos nossos actores não tinham ainda o hábito do palco, e por essa razão era preciso aprender de cor encenações inteiras, desde os movimentos de mão e de pé até os gestos de cabeça, aos olhares, às evoluções. Eu também velava por isso, esperando que de qualquer maneira o ponto garantiria o resto. No sábado à tarde a peça considerava-se pronta. (MAKARENKO,1980, p. 46).

\footnotetext{
${ }^{12}$ Recomenda-se importante contribuição para a pedagogia mundial a leitura de TOLSTOI, Leon. Obras pedagógicas. Moscou: Editora Progresso, 1988. 
Esses são alguns exemplos que Makarenko valoriza, a práxis social, os coletivos de educadores, de artes, a disciplina, o debate franco, modo de ministrar aulas, de se relacionar com os alunos, maneira de vestir, falar, não dar gargalhadas à toa, sem nexo e sem motivos. Além disso, há discursos e livros escritos por ele incluindo a formação política e pedagógica dos pais dos alunos, mostrados na obra O livro dos pais. Atribuímos, portanto, um destaque especial, pois é uma raridade termos autores que tiveram preocupações com a formação dos pais.

O livro dos pais, um compêndio pedagógico de orientações para educação de crianças e adolescentes escrito em 4 tomos focalizando assuntos como: tomo 1 - Família como coletividade]; tomo 2 - Educação moral e política na família e na escola]; tomo 3 - Educação através do trabalho e orientação profissional, tomo 4 - Educação do homem dirigida a felicidade "Como educar o homem para que seja feliz?” Para elucidar nossa exposição, mostramos a seguir passagens da mencionada brochura:

\section{Caros pais!}

Fique aqui dito, entre nós, que no seio da nossa confraria pedagógica a percentagem de maus artesãos no trabalho familiar não é de modo nenhum menos elevada que entre vós. É frequente, pelo contrário, ver crescer esplêndidas crianças no lar de pais que da ciência pedagógica não viram nunca nem a entrada de honra, nem a porta de serviço.

Mas a ciência pedagógica trata muito pouco das questões da educação familiar. Por isso é que os mais sábios nesta matéria, embora conheçam perfeitamente o seu problema, recorrem o mais possível, quando se trata da educação do seu próprio filho, ao bom senso e à sabedoria vulgares. Mais frequentemente do que outros talvez, essas pessoas pecam por uma fé ingênua na virtude de um "segredo" pedagógico". (MAKARENKO, s/d., p.22).

Pesquisar e buscar propagar a obra desse autor é tarefa fundamental para educadores, educandos, pais que almejam uma educação crítica impulsionada na esteira de uma reflexão empenhada com a formação do homem omnilaterial, comprometido com a felicidade, como escreve o autor em suas obras debatendo acerca da arte, da educação, da literatura, das novelas por ele escritas dos problemas da sociedade.

Dessa maneira, compreendemos que a pedagogia de Makarenko na União Soviética deu uma relevante contribuição à educação transformadora, trabalhando o homem no sentido da formação humana na sua totalidade na tentativa de transformar as velhas estruturas do Império que não desapareceram completamente com a revolução socialista, em pensamento e ações práxicas colocando o homem em movimentos buscando construir uma nova sociedade, uma nova ordem, na perspectiva de superar as classes sociais, as desigualdades, as diferenças 
econômicas, a divisão social do trabalho, a dicotomia entre trabalho intelectual e trabalho manual, descrito no conjunto da obra, de Marx, Engels, Lênin.

Nessa atmosfera de acontecimentos políticos, a participação ativa de Makarenko no processo revolucionário de 1917, fez dele um homem de enormes compromissos e responsabilidades. Sua atuação conjunta com outros trabalhadores em manifestações e vários ativistas formou em Makarenko a necessidade convicta de uma transformação, social, política, econômica, cultural e principalmente no campo da educação. Para tornar mais claras essas ideias, apresentamos a seguinte passagem de palestra ministrada pelo pedagogo que posteriormente comporia a sessão: As minhas concepções pedagógicas na obra Problemas da educação escolar, obra já citada do escritor:

Agora só para resumir as minhas palavras de introdução direi que todas essas questões são extraordinariamente difíceis, visto que as boas qualidades necessitam de anos para se formarem. Não se pode formar um caráter sem método ou através do imediatismo. Só se pode formar um caráter mediante a participação prolongada da pessoa na vida de uma coletividade corretamente organizada, disciplinada, forjada e orgulhosa de si mesma. Mas organizar uma experiência deste gênero significa obrigatoriamente arriscar. (MAKARENKO, 2010, p. 123).

Amparado no ideário das teses socialistas, Makarenko em sua obra-prima Poema Pedagógico narra em seus capítulos a construção física e teórica da Colônia Górki. O pedagogo ucraniano desenvolveu um processo educativo junto aos educadores e educandos e um método próprio na perspectiva de educação sob o ideário de uma educação socialista tendo como aporte as obras de Marx, Engels, Lênin. É o esse o sentimento que toma conta de Makarenko de construir uma educação socialista comprometida com a (trans)formação do homem, e por que não dizer com a formação do novo educador ${ }^{13}$, do novo educando, da nova mulher, ${ }^{14}$ como ele mesmo escreve nos clássicos Poema Pedagógico e Problemas da Educação Escolar:

Como na vida tive que, fundamentalmente resolver objectivos e problemas relacionados com a educação sofri muito com esta questão, quando me

${ }^{13}$ Conferir relevantes textos sobre a transformação da sociedade e e a construção da nova mulher em: Machel. Samora, Kollantai e outros. A libertação a mulher. São Paulo: Global Editora, 1979. "Como fazer triunfar a revolução sem libertar a mulher? Será possível liquidar o sistema de exploração mantendo uma parte da sociedade explorada? Não se pode liquidar só uma parte da exploração e da opressão, não se pode arrancar metade das raízes da erva ruim sem que esta renasça mais forte ainda a partir da outra metade que sobreviveu. Como fazer então a revolução sem mobilizar a mulher?”. (MACHEL \& KOLLANTAI, 1979, p. 18).

${ }^{14}$ Recomenda-se interessantes clássicos russos enfocando a construção da nova mulher e seus direitos sociais e sua atuação política. Conferir em: KOLLANTAI, Alexandra. A nova mulher e a moral sexual. São Paulo: Expressão Popular, 2008. Conferir também em: Kollantai, Alexandra. Marxismo e revolução sexual. São Paulo: Global editora, 1982.

\begin{tabular}{|c|c|c|c|c|}
\hline Qovista Dialectus & Ano 2 & n.7 & Setembro - Dezembro 2015 & p. $68-81$ \\
\hline
\end{tabular}


enviam educadores sem educação. Gastei vários anos de minha vida e de trabalho, pois é uma grande estupidez contar que um educador sem educação eduque alguém. Considerei que era melhor ter na coletividade quatro educadores talentosos do que 40 sem talento e sem educação. Com meus próprios olhos vi pessoas sem talento e sem educação trabalharem na coletividade. Que resultado poderia dar um trabalho destes? Só a desintegração da coletividade. Não pode haver outros resultados. (MAKARENKO, 1986, p. 101).

Makarenko nos ensina sobre a importância da implantação de atividades extracurriculares em todas as escolas, inclusive nas primárias, pois, além de completar a educação regular, torna a escola mais aprazível, estimulando os alunos a melhorar o desempenho escolar, como também as relações humanas. Pode-se contribuir para a educação através de atividades lúdicas e científicas ao mesmo tempo, a partir de concursos regulares de poesia, prosa, canto, teatro; no campo científico, incentivando círculos de estudos, grupos de trabalhos e pesquisas sobre assuntos importantes e de interesse da escola e da sociedade.

Entendo que a educação, por si só, não transforma o modo de vida de trabalho e ensino do povo. Makarenko, portanto, não espera transformar o mundo através da educação, mas compreende que esta é um instrumento importante para a luta pela emancipação dos trabalhadores. Para os socialistas, é necessária uma força produtiva que ponha em prática a ação revolucionária da classe operária. Para efeito de fundamentação, sobre o tema, o aludido pedagogo escreve:

Uma segunda qualidade muito importante por tom que é necessária a ser formada na instituição é a unidade da coletividade, a união estreita entre todos os seus membros. Nas relações internas, no trabalho cotidiano, os educandos podem "pressionar" um a outro quanto quiserem, criticar um a outro nas assembleias gerais, no Conselho, castigar um ao outro mas fora destas formas especiais de influência eles devem fazer justiça a cada educando antes de mais por ele é membro da mesma colectividade, defendêlos dos estranhos, não lhe causar desgosto algum, não o difamar. Esta unidade da colectividade deve manifestar-se com maior incidência durante trabalhos de urgência, de investida e durante uma grande luta comum. Nestas alturas não é preciso lembrar erros ou faltas cometidas por alguns camaradas. (MAKARENKO, 1986, p.168-169).

Como visto, Makarenko atua para além de uma teoria da educação, o proeminente escritor elabora e busca propagar a importância da superação do modo de produção capitalista e a construção de uma escola socialista coletiva. Os sentimentos de alegria e felicidade presentes na obra Poema Pedagógico, mostram as feições do autor de modo que ele mesmo tenta transmitir para os alunos gorkianos o bom senso e a alegria ao construírem novas 
perspectivas de vida, trabalho, educação, artes, esportes, música. Cada página virada uma vitória, assim foi o empenho de Makarenko juntamente com variados coletivos, edificar uma nova concepção de mundo, de universidade, de escola, de ser humano, de educador, de educando. É esse o pensamento que toma conta de Makarenko ao escrever os capítulos de Poema Pedagógico:

Nós vivemos com beleza e com alegria e com bom senso porque nós somos gente, por que temos uma cabeça sobre os ombros e porque é assim que queremos. E quem pode nos impedir? Não existe ninguém que possa tomar de nós o nosso trabalho e o nosso ganho. (MAKAREKNO, 1991, p.159, v. $3)$.

A educação proposta e vivenciada por Makarenko durante mais de três décadas se constrói também a partir da participação do povo, dos pais de alunos, da comunidade que tem interesse em edificar um processo educativo diferente do regime imperial czarista. Portanto, uma educação fundada nas teses revolucionárias se edifica, a partir da prática revolucionária constante do homem, da participação nos organismos sociais coletivos, na escola, no engajamento político e na concretude das relações sociais formadoras de consciência política. Dessa maneira, destacarei ideias fundamentais à práxis educativa de Makarenko como ponto ilustrativo da nossa exposição:

\section{NO POEMA PEDAGÓGICO}

Relevante obra de Makarenko narrando em 3 tomos a experiência da Colônia Gorki ${ }^{15}$, a reconstrução, os princípios, a natureza da educação, os destacamentos, a formação da célula Kosomol, ou seja, a juventude comunista, a fundação de coletivos de educação, artes, ciências, o embrião das faculdades obreiras, as bases do balé, canto coral, arte dramática, oficinas de teatro e de trabalho, a articulação entre trabalho / educação com as necessidades emergenciais que o país exigia à época. Narrando de modo vivo as vitórias, as derrotas, as alegrias, as tristezas, as dificuldades.

O Poema Pedagógico enfoca o nascimento da pedagogia socialista de Makarenko na União Soviética desde o princípio, mostrando quando o pedagogo ucraniano iniciou seu trabalho pedagógico no meio rural, as pressões que sofreu, a falta de material pedagógico e alimentação, os furtos constantes no campo. Considerado pela escritora russa Belinky (1989)

${ }^{15}$ Devido a questão tempo-espaço não me deterei de modo detalhado na célebre obra Poema Pedagógico, de Makarenko. 
“o Poema Pedagógico de Makarenko é uma epopeia, um poema épico”, assim como foi a vida pedagógica do escritor em relevo.

Esses três volumes marcam a vida de Makarenko e a educação crítica, abordam as primeiras lições do socialismo na União Soviética trabalhando também entre outros relevantes tópicos, a fundação da banda de música, do grupo de teatro e suas múltiplas atividade artísticas e culturais desenvolvidas pela coletividade na Colônia Górki. Ademais, se expressa o autor da brochura em tela:

Claro que tínhamos escritores, tínhamos artistas também, sem essa gente, nenhum coletivo pode sobreviver, sem eles nem mesmo seria possível fazer um jornal mural. Mas aqui eu devo confessar, consternado, dos Gorkianos não saíram nem escritores nem artistas, não saíram não porque lhe faltasse talento, mas por outros motivos. (MAKARENKO, 1989, p. 259, v. 3).

\section{NA OBRA PROBLEMAS DA EDUCAÇÃO ESCOLAR}

Volume em que o escritor apresenta os objetivos da educação, a autogestão nos destacamentos de jovens como ferramenta fundamental para experiência práxica e de vida, metodologia para a organização do trabalho educativo, os métodos de educação, a estrutura orgânica da coletividade, os princípios pedagógicos da formação do homem socialista, a educação laboral, o estilo de trabalho com a coletividade, os órgãos de autogestão. Vejamos importante reflexão do autor no seguinte trecho:

Por objetivo da educação entendo um programa da personalidade humana, um programa do caráter humano, com a particularidade de que no conceito de caráter incluo todo o conteúdo da personalidade, isto é: o caráter das manifestações externas e da convicção íntima, a educação política e os conhecimentos incluo, então o quadro inteiro da personalidade humana; considero que nós, pedagogos, devemos ter um programa da personalidade humana para qual devemos dirigir as nossas aspirações. (MAKARENKO, 1986, p. 60).

\section{EM CONFERÊNCIAS SOBRE EDUCAÇÃO INFANTIL}

Importante compêndio que, para nós, educadores brasileiros preocupados com o presente e com o futuro da educação das famílias das camadas populares merece os nossos aplausos, pois esta obra mostra a relevância da educação infantil para os pais, para os educadores e para todos aqueles envolvidos com a educação e com o processo de formação da consciência crítica e política canalizando para transformação da sociedade a emancipação humana via lutas sociais. O livro mostra um conjunto de conferências abordando tópicos

\begin{tabular}{|c|c|c|c|c|}
\hline QRomita Oialectus & Ano 2 & n.7 & Setembro - Dezembro 2015 & p. $68-81$ \\
\hline
\end{tabular}


essenciais no debate sobre educação e formação do educador e do educando. São as seguintes conferências: Condições gerais da educação familiar, A autoridade paterna, disciplina, O jogo, O trabalho da educação familiar, Economia familiar, educação de hábitos culturais, Educação Sexual. Desse modo, apresento relevante passagem da obra supracitada:

\begin{abstract}
Neste caso, os pais dedicam mais atenção aos filhos que no caso anterior (refere-se a autoridade de presunção); trabalham mais, porém o fazem como burocratas, convencidos de que sua palavra é sagrada e de que os filhos devem escutá-las com devoção. Usam um tom frio para comunicar suas resoluções, as quais uma vez proferidas, transforma-se imediatamente em lei. Trata-se sobretudo de gente que tem medo de que os filhos pensem que o pai pode errar, que não é homem decidido. Se ele disse: "Amanhã vai chover, por isso não podemos ir passear" então mesmo que no dia seguinte o tempo esteja bom, já ficou estabelecido que não se pode passear. Um filme não lhe agradou: em consequência, haverá uma proibição de ir a qualquer cinema, mesmo que haja bons filmes, Impôs um castigo e mais tarde descobre que a criança não era tão culpada como parecia: o pai por nada deste mundo muda sua atitude; uma vez imposto o castigo, este deve ser cumprido. Todos os dias encontra motivos para punir e em cada movimento do filho vê uma transgressão da ordem e da legalidade, importunando-o com novas leis e disposições. A vida da criança, seus interesses, seu crescimento, passam-lhe despercebidos; não vê coisa além de sua chefia burocrática da família. (MAKARENKO, 1981, p. 29-30).
\end{abstract}

A pedagogia de Makarenko se notabilizou pela beleza de seu trabalho e de sua obra educativa e social, articulada nas instâncias ditas como socialismo ou socialismo real. Mormente seu trabalho em conjunto com outros educadores socialistas fez da educação uma arte de ensinar e aprender criando uma escola e uma vida em movimento. Movimentos e mobilizações políticas constantes constituindo no cotidiano das relações e das lutas sociais, verdadeiras oficinas de arte-educação, vida e trabalho. $\mathrm{O}$ pedagogo associou a educação às necessidades dos coletivos a realidade histórica que a comunidade e a sociedade necessitavam à época. Makarenko, através do trabalho coletivo, transformou a vida e a educação de crianças e adolescentes pobres sem direção, em cientistas de diversas áreas do conhecimento, realizando a partir da práxis a construção de um novo devir, de um novo homem filosófico de carne e osso. Uma pedagogia mundial! Uma tarefa histórica fenomenal!

\title{
REFERÊNCIAS
}

CAPRILES, René. Makarenko: o nascimento da pedagogia socialista. [s.1.]: Scipione, 1989.

\begin{tabular}{|c|c|c|c|c|}
\hline Rovista Dialeatus & Ano 2 & n.7 & Setembro - Dezembro 2015 & p. $68-81$ \\
\hline
\end{tabular}


FILONOV. G.N. Anton Makarenko. Tradução de Ester Buffa. Recife: Fundação Joaquim Nabuco, 2010. (Coleção Educadores).

KOLLANTAI, Alexandra. Marxismo e revolução sexual. São Paulo: Global Editora, 1982. A nova mulher e a moral sexual. São Paulo: Expressão Popular, 2008.

LUEDEMANN, Cecília da Silveira. Anton Makarenko, vida e obra: a pedagogia da revolução. São Paulo: Expressão Popular, 2002.

LÊNIN. V. I. O Estado e a revolução. São Paulo: Global Editora, 1987.

1905 - Jornadas socialistas- Contagem. Minas Gerais: Editora História, 1980.

Que fazer? São Paulo: Hucitec, 1988.

MAIA, Lucíola Andrade \& PINHEIRO, Carísia Maia. Mestres da educação socialista: Anton Makarenko e Florestan Fernandes. Fortaleza: Centro Cultural do Benfica, 2010.

MAKARENKO, Anton. Conferências sobre educação infantil. São Paulo: Editora Moraes, 1981.

. Problemas da educação escolar. Moscou: Edições Progresso, 1986.

Poema pedagógico. 2. ed. Lisboa: Editora Livros Horizonte, 1980. v.1.

Poema pedagógico. 2. ed. Editora: Lisboa: Livros Horizonte, 1980. v. 2.

Poema pedagógico. 2. ed. São Paulo: Brasiliense, 1991. v. 3.

Livro dos pais I. Tradução de M. Rodrigues Martins. Lisboa: [s.n. s.d.].

Livro dos pais II. Tradução de M. Rodrigues Martins. Lisboa: [s.n.], 1981.

VÁZQUEZ, Adolfo Sánchez. Filosofia da práxis. São Paulo: Expressão Popular, 2007.

TOLSTOI, Leon. Obras pedagógicas. Tradução de J.M. Milhazes Pinto. Moscou: Edições Progresso, 1988.

TROTSKY. A revolução de 1905. São Paulo: Global Editora, [s.d]. 


\begin{tabular}{|c|c|c|c|c|}
\hline Rovista Dialectus & Ano 2 & n.7 & Setembro - Dezembro 2015 & p. $68-81$ \\
\hline
\end{tabular}

